\title{
Understanding off-label use and the new challenges
}

\author{
Marc Dooms \\ From 7th European Conference on Rare Diseases and Orphan Products (ECRD 2014)
}

As there are several thousands of rare disorders and only some tents of orphan drugs authorized in Europe, off-label use of medicinal products occurs frequently in the diagnosis, prevention and treatment of rare diseases.

Off-label use is the use of a medicinal product for another indication, another patient group, another dose or by another route of administration as indicated in the package insert. This so-called off-label use is suggested by a similar mode of action or a similar pathology. The competent authorities complain about this therapeutic usage because there is no evidence of their safety and efficacy. Payers hesitate to reimburse this non-validated use. The only responsible person for this use is the prescriber. Sometimes the patient will be asked to sign an informed consent. Normalization of this off-label use can only be done by the sponsor not by the medical profession or the patient organization. Pharmaceutical companies are not allowed to mention the off-label use to the medical profession: recently settlements are reached against companies to resolve allegations of offlabel promotion of their orphan pharmaceutical products (Tobi, Trisenox, Xyrem). Some pharmaceutical companies bring the old substance on the market as a so-called new "repurposed" or "rediscovered" medicinal product with a higher price (Litak, Quenobilan, Savene, Xenbilox). When the medicinal product is taken from the market (deflazacort, mexiletine) the off-label users lose their only treatment.

At the faculty of pharmacy of the University in Leuven, a group of students performed in-depth interviews to all the stakeholders in this process and identified the main obstacles to regularization. The Belgian Health Care Knowledge Center [https://kce.fgov.be/] will further explore these recommendations and give advice to the public authorities to take further actions. The Belgian Minister of Health already proposed a Royal Decree to

University Hospitals Leuven, Belgium any medium, provided the original work is properly cited. The Creative Commons Public Domain Dedication waiver (http:// creativecommons.org/publicdomain/zero/1.0//) applies to the data made available in this article, unless otherwise stated. 